\title{
Multidrug-Resistant Hypervirulent Group B Streptococcus in Neonatal Invasive Infections, France, 2007-2019
}

\author{
Céline Plainvert, Constantin Hays,1 Gérald Touak, Caroline Joubrel-Guyot,2 \\ Nicolas Dmytruk, Amandine Frigo, Claire Poyart, Asmaa Tazi
}

We analyzed group B Streptococcus (GBS) neonatal invasive infections reported during 2007-2019 in France. The hypervirulent clonal complex (CC) 17 GBS was responsible for $66 \%(827 / 1,262)$ of cases. The role of CC17 GBS increased over time ( $p$ for trend $=0.0001$ ), together with the emergence of a multidrug-resistant CC17 GBS sublineage.

roup B Streptococcus (GBS; Streptococcus agalac$\checkmark$ tiae) is the leading cause of neonatal invasive infections worldwide (1). Despite appropriate antimicrobial drug therapy, the global burden of GBS neonatal infections remains substantial, with up to $10 \%$ mortality and 30\% neurologic sequelae in surviving infants (2). Two GBS-associated syndromes are distinguished in neonates: early-onset disease (EOD), which occurs during the first week of life, and late-onset disease (LOD), which occurs after the first week (1). In EOD, the neonate is infected by GBS-contaminated maternal secretions during parturition; thus, strategies based on intrapartum antibiotic prophylaxis have drastically diminished its incidence. In contrast, the pathophysiology of LOD remains elusive, and its incidence remains stable $(3,4)$. Thus, LOD has become the main GBS-associated syndrome in France and other countries in Europe and in North America $(4,5)$. LOD is largely attributable to a particular GBS clone of serotype III, designated the hypervirulent clonal complex (CC) 17 GBS $(3,6,7)$. Recent epidemiologic data from Canada,

Author affiliations: Assistance Publique-Hôpitaux de Paris Centre Université de Paris, Paris, France (C. Plainvert, C. Hays,

C. Joubrel-Guyot, N. Dmytruk, A. Frigo, C. Poyart, A. Tazi); Institut Cochin, Paris (C. Plainvert, G. Touak, C. Poyart, A. Tazi); FHU Prema, Paris (C. Plainvert, C. Poyart, A. Tazi); Université de Paris, Paris (C. Hays, C. Joubrel-Guyot, C. Poyart, A. Tazi)

DOI: https://doi.org/10.3201/eid2611.201669
China, and Portugal reported the emergence of a multidrug-resistant (MDR) sublineage of CC17 GBS that exhibits acquired nonsusceptibility to 4 antimicrobial categories, namely tetracyclines, aminoglycosides, macrolides, and lincosamides (8-10). We analyzed neonatal invasive GBS diseases reported to the French National Reference Center for Streptococci during 2007-2019 and investigated the role of the hypervirulent clone over this period.

\section{The Study}

GBS isolates were sent to the National Reference Center by correspondents located throughout the national territory on a voluntary basis. Only invasive infections, such as GBS isolated from a normally sterile site, were considered for this study. A total of 1,262 neonatal invasive infections (EOD, $\mathrm{n}=394,31 \%$; LOD, $\mathrm{n}=868,69 \%$ ) were reported during 2007-2019. The annual number of cases increased significantly over time as a result of a marked rise in LOD cases since 2013 (Appendix Figure 1, https:/ / wwwnc.cdc. gov/EID/article/26/11/20-1669-App1.pdf). Bacteremia without focus was the main clinical presentation during both EOD and LOD (Table 1). Meningitis represented a frequent complication and was more common in LOD, in which it affected nearly half of infants $(p<0.0001 ;$ Table 1$)$. The proportion of meningitis during LOD dropped significantly over time, from $69 \%$ $(95 \%$ CI $51 \%-83 \%)$ in 2007 to $33 \%$ (95\% CI 25\%-43\%) in 2019 ( $p$ for trend $=0.008$; Appendix Figure 2). The French recommendations for lumbar puncture indication in neonates did not change during the study period. This observation, together with the increased annual number of cases, suggests a better reporting

\footnotetext{
${ }^{1}$ Current affiliation: APHP-Nord (St. Louis) Université de Paris, Paris, France.

${ }^{2}$ Current affiliation: Le Raincy Hospital, Montfermeil, France.
} 
of bacteremia and a better representativeness of our collection over time.

Molecular capsular typing of the 1,262 GBS isolates was performed (11) (Table 1). Serotype III was overrepresented, especially in LOD, accounting for $57 \%(95 \%$ CI $52 \%-62 \% ; n=223 / 394)$ of EOD cases and $82 \%(95 \%$ CI $79 \%-84 \%$; $\mathrm{n}=712 / 868)$ of LOD cases. Identification of the hypervirulent CC17 GBS, a highly homogenous $\mathrm{CC}$ that includes the sequence type (ST) 17 , was performed using a specific PCR (12) and showed that it caused $66 \%$ (95\% CI 63\%-68\%; n $=827 / 1,262)$ of GBS neonatal invasive disease. CC17 GBS prevalence was particularly overwhelming in LOD $(74 \%$, 95\% CI 71\%-77\%) compared with EOD $(48 \%, 95 \%$ CI $43 \%-53 \%$; p $<0.0001)$ and, during EOD, in cases of meningitis compared with bacteremia $(68 \%, 95 \%$ CI $59 \%-77 \%$ vs. $41 \%, 95 \%$ CI $36 \%-47 \%$; $\mathrm{p}<0.0001)$. Furthermore, CC17 GBS prevalence increased by $\approx 50 \%$ over the study period, rising from $53 \%$ (95\% CI $40 \%-65 \%$ ) in 2007 to $76 \%$ (95\% CI 68\%$82 \%$ ) in 2019 ( $p$ for trend $=0.0001$; Figure 1). This evolution was linked with its prevalence in LOD, which gradually increased from 59\% (95\% CI 41\%-75\%) to $85 \%$ (95\% CI 77\%-91\%) of the cases during 2007-2019 ( $\mathrm{p}$ for trend $=0.025$ ).

We determined the susceptibility of the 1,262 GBS isolates to antimicrobial drugs and performed the detection of resistance genes as previously described (13). All isolates were susceptible to penicillin, amoxicillin, and vancomycin. Resistance to tetracyclines did not vary through the study period and concerned $91 \%(95 \%$ CI $89 \%-92 \%)$ of the strains, owing to the genetic determinant tet(M) in $92 \%$ of the cases (data not shown). Only 3 isolates $(0.2 \%$, $95 \%$ CI $0.1 \%-0.7 \%$ ) showed high-level resistance to gentamicin, but high-level resistance to amikacin increased from $0 \%$ (95\% CI 0\%-7\%) in 2007 to $18 \%$ (95\% CI 12\%-26\%) in 2019 (p for trend <0.0001; Table 2).
Table 1. Clinical manifestations, serotypes, and CC17 prevalence of group B Streptococcus neonatal invasive infections, France, 2007-2019*

\begin{tabular}{|c|c|c|c|}
\hline $\begin{array}{l}\text { Clinical } \\
\text { manifestation }\end{array}$ & EOD, no. $(\%)$ & LOD, no. (\%) & $p$ value \\
\hline Bacteremia & $298(75.6)$ & $442(50.9)$ & $<0.0001 \#$ \\
\hline la & $69(23.2)$ & $45(10.2)$ & $<0.0001^{* *}$ \\
\hline $\mathrm{Ib}$ & $13(4.4)$ & $8(1.8)$ & \\
\hline II & $30(10.1)$ & $6(1.4)$ & \\
\hline III & $149(50.0)$ & 359 (81.2) & \\
\hline IV & $6(2.0)$ & $6(1.4)$ & \\
\hline V & $26(8.7)$ & $18(4.1)$ & \\
\hline Others $†$ & $3(1.0)$ & 0 & \\
\hline CC17 & $122(40.9)$ & $334(75.6)$ & $<0.0001 \#$ \\
\hline Meningitis $\ddagger$ & $95(24.1)$ & 397 (45.7) & $<0.0001 \#$ \\
\hline la & $15(15.8)$ & $39(9.8)$ & $0.33^{* *}$ \\
\hline $\mathrm{lb}$ & $2(2.1)$ & $12(3.0)$ & \\
\hline II & 0 & $7(1.8)$ & \\
\hline III & $74(77.9)$ & $329(74.4)$ & \\
\hline IV & $2(2.1)$ & $2(0.5)$ & \\
\hline V & $2(2.1)$ & $8(2.0)$ & \\
\hline CC17 & $65(68.4)$ & $285(71.8)$ & $0.52 \#$ \\
\hline Others§ & $1(0.3)$ & $29(3.3)$ & $<0.0001 \#$ \\
\hline III & 0 & 24 (82.8) & \\
\hline Others & 1 & $5(17.2)$ & \\
\hline $\mathrm{CC} 17$ & 0 & $21(72.4)$ & \\
\hline Total & $394(100)$ & $868(100)$ & \\
\hline \multicolumn{4}{|c|}{$\begin{array}{l}{ }^{*} \mathrm{CC} \text {, clonal complex; EOD, early-onset disease; LOD, late-onset disease. } \\
\text { †lncluding serotypes VI ( } 2 \text { isolates) and VIII ( } 1 \text { isolate). } \\
\text { †GBS recovered from cerebrospinal fluid ( } 470 \text { cases) or GBS bacteremia } \\
\text { associated with a cellular reaction in the cerebrospinal fluid ( }>20 \\
\text { leukocytes } / \mathrm{mm}^{3} \text { ) and consistent clinical findings ( } 4 \text { EOD and } 18 \text { LOD } \\
\text { cases). } \\
\text { \$lncluding bone and joint and skin and soft tissue infections. } \\
\text { TIncluding serotypes la ( } 3 \text { isolates), Ib ( } 2 \text { isolates), and V ( } 1 \text { isolate). } \\
\# \chi^{2} \text { test for the distribution of the clinical manifestations in EOD and LOD. } \\
{ }^{* *} \chi^{2} \text { test for serotype distribution or CC17 proportion in EOD and LOD } \\
\text { during either bacteremia or meningitis. }\end{array}$} \\
\hline
\end{tabular}

Similarly, resistance to erythromycin increased from $22 \%(95 \%$ CI $13 \%-34 \%)$ to $30 \%$ (95\% CI $23 \%-38 \%$; p for trend $=0.019)$. Resistance to erythromycin was mostly the result of modifications of the ribosomes that confer cross resistance to lincosamides and are encoded by the genetic determinants $\mathrm{erm}(\mathrm{B})(64 \%)$, $\operatorname{erm}(\mathrm{A} / \mathrm{TR})(13 \%)$, or $\operatorname{erm}(\mathrm{T})(1 \%)$, and in $22 \%$ of the cases were the result of an efflux mechanism encoded by the genetic determinant mef.

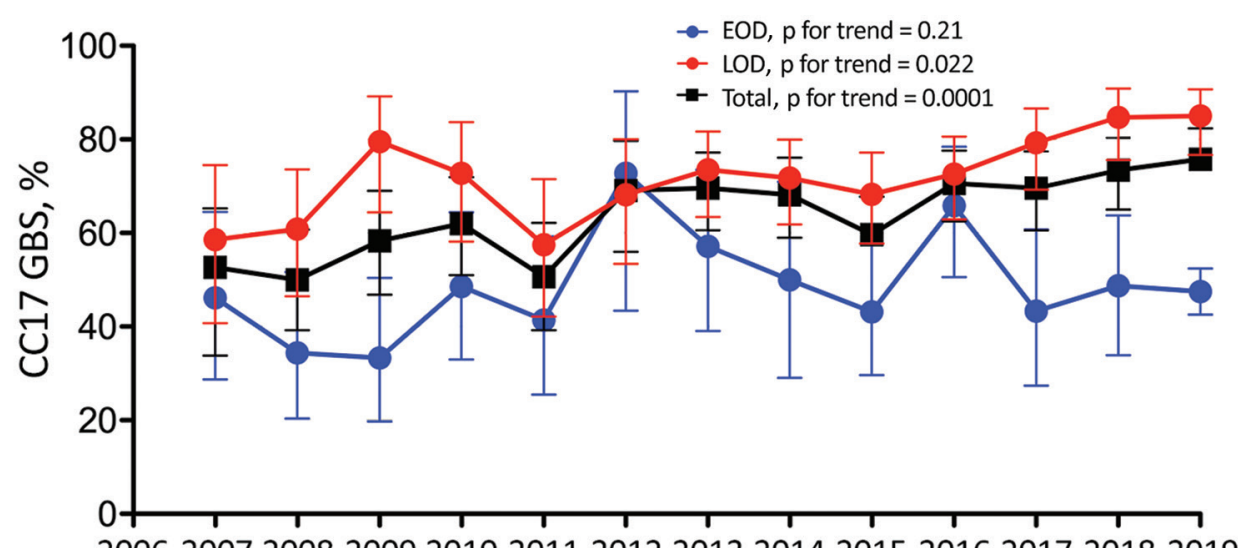

Figure 1. Increasing responsibility of the hypervirulent $\mathrm{CC} 17$ clone in GBS neonatal invasive diseases, France, 2007-2019. The annual proportion of infections caused by CC17 GBS during EOD (blue line), LOD (red line), and overall (black line) are represented. Results are expressed as percentage of total GBS isolates per syndrome and per year. Error bars indicate $95 \%$ Cls. Evolutionary trends were analyzed using 2-tailed nonparametric Spearman correlation. CC, clonal complex; EOD, early-onset disease; GBS, group B Streptococcus; LOD, late-onset disease. 
Group B Streptococcus Neonatal Infections, France

Table 2. Resistance to erythromycin and high-level resistance to amikacin of GBS neonatal isolates, France, 2007-2019* Total GBS isolates, resistance, $\%(95 \% \mathrm{Cl})$

\begin{tabular}{|c|c|c|c|c|}
\hline \multirow[b]{2}{*}{ Year } & & \\
\hline & Erythromycin & Amikacin & Erythromycin & Amikacin \\
\hline 2007 & $21.8(13.0-34.4)$ & $0.0(0.0-6.5)$ & $17.2(7.6-34.6)$ & $0.0(0.0-11.7)$ \\
\hline 2008 & $9.0(4.4-17.4)$ & $1.3(0.2-6.9)$ & $5.1(1.4-16.9)$ & $0.0(0.0-7.7)$ \\
\hline 2009 & $19.4(12.0-30.0)$ & $1.4(0.3-7.5)$ & $7.1(2.5-19.0)$ & $0.0(0.0-9.0)$ \\
\hline 2010 & $21.5(13.9-31.8)$ & $2.5(0.7-8.8)$ & $16.3(8.5-29.0)$ & $0.0(0.0-8.0)$ \\
\hline 2011 & $21.7(13.6-32.8)$ & $1.5(0.3-7.8)$ & $8.6(3.0-22.4)$ & $0.0(0.0-8.8)$ \\
\hline 2012 & $10.9(5.1-21.8)$ & $3.6(1.0-12.3)$ & $5.3(1.5-17.3)$ & $2.3(0.4-11.8)$ \\
\hline 2013 & $17.4(11.6-25.3)$ & $3.5(1.4-8.6)$ & $10.0(5.2-18.5)$ & $0.0(0.0-4.2)$ \\
\hline 2014 & $19.1(12.8-27.4)$ & $11.8(7.0-19.2)$ & $10.7(5.5-19.7)$ & $6.5(3.0-13.5)$ \\
\hline 2015 & $25.6(18.8-33.7)$ & $14.7(9.6-21.9)$ & $23.4(15.3-34.0)$ & $10.6((5.7-18.9)$ \\
\hline 2016 & $18.4(12.8-25.7)$ & $11.8(7.4-18.3)$ & $20.8(13.9-30.0)$ & $8.4(4.3-15.7)$ \\
\hline 2017 & $25.9(18.7-34.7)$ & $9.8(5.6-16.7)$ & $20.5(13.0-30.8)$ & $9.8(5.0-18.1)$ \\
\hline 2018 & $33.1(25.4-41.7)$ & $16.9(11.4-24.5)$ & 29.7 (21.3-39.7) & $22.4(14.8-32.3)$ \\
\hline 2019 & $29.7(22.5-38.1)$ & $18.0(12.3-25.5)$ & $28.6(20.6-38.2)$ & $14.1(9.1-21.1)$ \\
\hline $\mathrm{p}$ for trend $\dagger$ & 0.019 & $<0.0001$ & 0.0042 & $<0.0001$ \\
\hline
\end{tabular}

Next, we specifically investigated CC17 GBS resistance to erythromycin and amikacin and found an increase over the study period from $17 \%$ $(95 \%$ CI $8 \%-35 \%)$ to $29 \%(95 \%$ CI $21 \%-38 \%$; p for trend $=0.0042$ ) for erythromycin resistance and from $0 \%(95 \%$ CI $0 \%-11 \%)$ to $14 \%(95 \%$ CI $9 \%-21 \%$; p for trend $<0.0001)$ for amikacin resistance (Table 2). We postulated that these evolutionary trends were attributable to the emergence of the MDR CC17 GBS sublineage, which exhibits resistance to tetracyclines, macrolides, lincosamides, and amikacin as a result of the replacement of the pilus island 1 genetic locus by mobile genetic elements carrying the resistance determinants tet $(\mathrm{O}), \operatorname{erm}(\mathrm{B})$, and $a p h A-3$ $(8,9)$. The proportion of CC17 GBS harboring tet $(\mathrm{O})$, erm(B), and aphA-3 among neonatal GBS isolates increased from $0 \%(95 \%$ CI $0 \%-6 \%)$ in 2007 to $14 \%$ (95\% CI 9\%-21\%) in 2019 ( $\mathrm{p}$ for trend $<0.0001$; Figure 2). Whole-genome sequencing of 8 of these MDR CC17 GBS (Appendix Table) confirmed the replacement of the pilus island 1 locus by large integrative and conjugative elements (ICEs) similar to those previously described in China and Canada $(8,9)$. Interrogation of the ICEberg database (http://db-mml.sjtu.edu. $\mathrm{cn} /$ ICEberg/) showed that these ICEs displayed the highest sequence similarity (92\%-98\%; Appendix Figure 3), with the GBS ICESag37 described in a CC10 isolate responsible for a neonatal bacteremia in China (14).

\section{Conclusions}

We analyzed a total of 1,262 neonatal invasive infections over a 13-year study period in France, which represents $\approx 30 \%$ of the total national estimated cases (4). A selection bias toward the more severe cases cannot be excluded. However, the proportions of EOD and LOD and the associated clinical manifestations described here are very close to the national estimations. Thus, we can assume that our study reflects the national epidemiology without major discrepancies.

Figure 2. Increasing

prevalence of MDR CC17 GBS among neonatal invasive isolates, France, 2007-2019. The annual proportion of infections caused by MDR CC17 GBS, such as those harboring the determinants $\operatorname{tet}(\mathrm{O}), \operatorname{erm}(\mathrm{B})$, and aphA3 , during EOD (blue line), LOD (red line) and overall (black line) are represented. Results are expressed as percentage of total GBS isolates per syndrome and per year. Error bars indicate 95\% Cls. Evolutionary trends were analyzed using 2-tailed

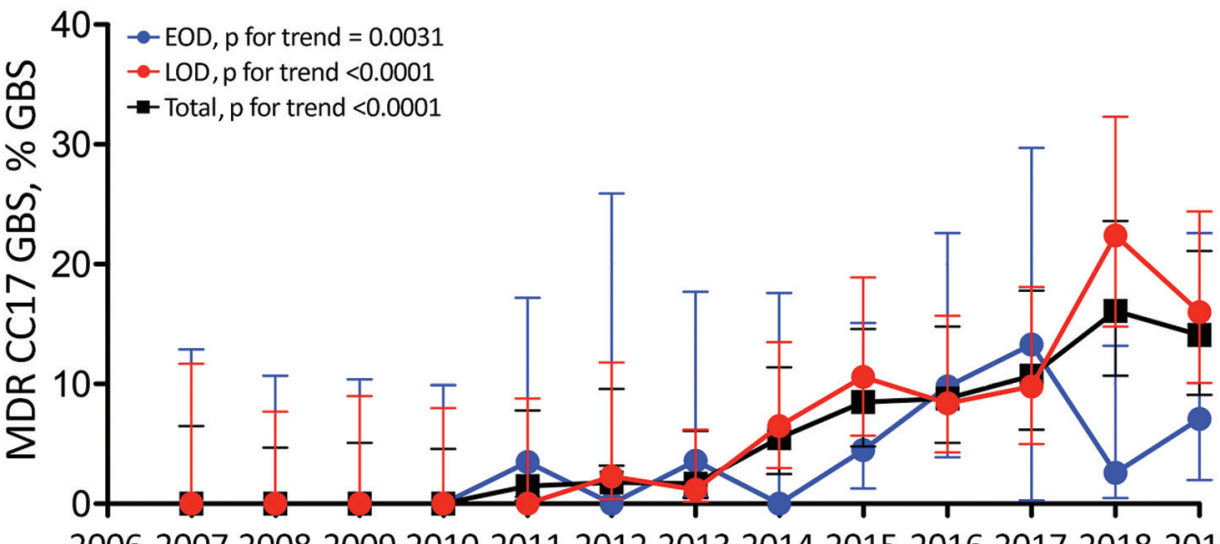
nonparametric Spearman correlation. CC, clonal complex; EOD, early-onset disease; GBS, group B Streptococcus; LOD, late-onset disease; MDR, multidrug-resistant. 
We observed a higher reporting of LOD in contrast to EOD over the 13-year study period. This trend mirrors the data from the surveillance network in France, which show a continuous increase in LOD incidence with an overall $65 \%$ rise over the past 20 years (4). We describe a growing prevalence of the hypervirulent CC17 GBS and of its MDR sublineage in LOD, which might account for the increasing incidence of this syndrome. Whether these trends are the result of a higher tropism of the MDR sublineage for neonatal infections or merely of its selection and clonal expansion as a result of antibiotic selection pressure requires further investigation. Given the worldwide expanding burden of GBS LOD, the adaptability of GBS to its environment through horizontal gene transfer (15), and the resulting potential reduction of the therapeutic arsenal against this major neonatal pathogen, our results reinforce the need for a continued surveillance of GBS diseases and for the development of alternative preventive strategies.

\section{Acknowledgments}

We thank Philippe Glaser for helpful discussion. We thank all of the correspondents of the French National Center for Streptococci.

This work was supported by the University of Paris, the Assistance Publique Hôpitaux de Paris, and Santé Publique France.

\section{About the Author}

Dr. Plainvert works at the French National Reference Center for Streptococci within the University Hospitals Paris Centre, Paris, France. Her main research interests focus on the epidemiology and pathogenicity of group A and group B Streptococcus.

\section{References}

1. Edwards MS, Nizet V, Baker CJ. Group B streptococcal infections. In: Infectious diseases of the fetus and newborn infant. 7th ed. Remington JS, Klein JO, Wilson CB, Nizet V, Maldonado Y, editors. Philadelphia: Elsevier; 2011. p. 419-69.

2. Libster R, Edwards KM, Levent F, Edwards MS, Rench MA, Castagnini LA, et al. Long-term outcomes of group B streptococcal meningitis. Pediatrics. 2012;130:e8-15. https:/ / doi.org/10.1542/ peds.2011-3453

3. Bekker V, Bijlsma MW, van de Beek D, Kuijpers TW, van der Ende A. Incidence of invasive group B streptococcal disease and pathogen genotype distribution in newborn babies in the Netherlands over 25 years: a nationwide surveillance study. Lancet Infect Dis. 2014;14:1083-9. https:/ / doi.org/10.1016/S1473-3099(14)70919-3

4. Santé Publique France. Bulletin of the bacterial invasive infections surveillance network 2018 [cited 2020 Jan 30]. http:/ / invs.santepubliquefrance.fr/Dossiers-thematiques/
Maladies-infectieuses/Maladies-a-prevention-vaccinale/ Infections-invasives-d-origine-bacterienne-Reseau-EPIBAC/ Bulletin-du-reseau-de-surveillance-des-infections-invasivesbacteriennes

5. Madrid L, Seale AC, Kohli-Lynch M, Edmond KM, Lawn JE, Heath PT, et al. Infant group B streptococcal disease incidence and serotypes worldwide: systematic review and meta-analyses. Clin Infect Dis. 2017;65(suppl2):S160-72. https://doi.org/10.1093/cid/cix656

6. Joubrel C, Tazi A, Six A, Dmytruk N, Touak G, Bidet P, et al. Group B Streptococcus neonatal invasive infections, France 2007-2012. Clin Microbiol Infect. 2015;21:910-6. https://doi.org/10.1016/j.cmi.2015.05.039

7. Teatero S, McGeer A, Low DE, Li A, Demczuk W, Martin I, et al. Characterization of invasive group B Streptococcus strains from the greater Toronto area, Canada. J Clin Microbiol. 2014;52:1441-7. https:/ / doi.org/10.1128/ JCM.03554-13

8. Campisi E, Rosini R, Ji W, Guidotti S, Rojas-López M, Geng G, et al. Genomic analysis reveals multi-drug resistance clusters in group B Streptococcus CC17 hypervirulent isolates causing neonatal invasive disease in southern mainland China. Front Microbiol. 2016;7:1265. https:/ / doi.org/ 10.3389/fmicb.2016.01265

9. Teatero S, Ramoutar E, McGeer A, Li A, Melano RG, Wasserscheid J, et al. Clonal complex 17 group $B$ Streptococcus strains causing invasive disease in neonates and adults originate from the same genetic pool. Sci Rep. 2016;6:20047. https://doi.org/10.1038/srep20047

10. Martins ER, Pedroso-Roussado C, Melo-Cristino J, Ramirez M; Portuguese Group for the Study of Streptococcal Infections. Streptococcus agalactiae causing neonatal infections in Portugal (2005-2015): Diversification and emergence of a CC17/PI-2b multidrug resistant sublineage. Front Microbiol. 2017;8:499. https://doi.org/10.3389/fmicb.2017.00499

11. Imperi M, Pataracchia M, Alfarone G, Baldassarri L, Orefici G, Creti R. A multiplex PCR assay for the direct identification of the capsular type (Ia to IX) of Streptococcus agalactiae. J Microbiol Methods. 2010;80:212-4. https://doi.org/10.1016/j.mimet.2009.11.010

12. Lamy M-C, Dramsi S, Billoët A, Réglier-Poupet H, Tazi A, Raymond J, et al. Rapid detection of the "highly virulent" group B Streptococcus ST-17 clone. Microbes Infect. 2006;8:1714-22. https:// doi.org/10.1016/j.micinf.2006.02.008

13. Hays C, Louis M, Plainvert C, Dmytruk N, Touak G, Trieu-Cuot $P$, et al. Changing epidemiology of group $B$ Streptococcus susceptibility to fluoroquinolones and aminoglycosides in France. Antimicrob Agents Chemother. 2016;60:7424-30. https:/ / doi.org/10.1128/AAC.01374-16

14 Zhou K, Xie L, Han L, Guo X, Wang Y, Sun J. ICESag37, a novel integrative and conjugative element carrying antimicrobial resistance genes and potential virulence factors in Streptococcus agalactiae. Front Microbiol. 2017;8:1921. https://doi.org/10.3389/fmicb.2017.01921

15. Da Cunha V, Davies MR, Douarre P-E, Rosinski-Chupin I, Margarit I, Spinali S, et al.; DEVANI Consortium. Streptococcus agalactiae clones infecting humans were selected and fixed through the extensive use of tetracycline. Nat Commun. 2014;5:4544. https://doi.org/10.1038/ ncomms5544

Address for correspondence: Asmaa Tazi, Service de Bactériologie, Hôpital Cochin, 27 rue du Faubourg Saint-Jacques, 75014 Paris, France; email: asmaa.tazi@aphp.fr 